\title{
IGF-binding protein-1 inhibits IGF effects on adipocyte function: implications for insulin-like actions at the adipocyte
}

\author{
K W Siddals ${ }^{1}$, M Westwood ${ }^{2}$, J M Gibson ${ }^{1,2}$ and A White ${ }^{1,2}$ \\ ${ }^{1}$ Diabetes and Endocrinology, Hope Hospital, Salford M6 8HD, UK \\ ${ }^{2}$ Endocrine Sciences Research Group, School of Biological Sciences, Faculty of Medicine, University of Manchester, Manchester M13 9PT, UK \\ (Requests for offprints should be addressed to A White, Endocrine Sciences Research Group, Stopford Building, University of Manchester, Oxford Road, \\ Manchester M13 9PT, UK; Email: awhite@man.ac.uk)
}

\begin{abstract}
IGF action in vivo is acutely regulated by IGF-binding protein-1 (IGFBP-1) and its phosphorylation state is implicated in modulating these effects. Since IGFs have an important regulatory role in adipocyte function, we investigated the effects of phosphorylated IGFBP-1 (pIGFBP-1) and non-phosphorylated IGFBP-1 (npIGF BP-1) on 3T3-L1 preadipocyte proliferation and adipocyte metabolism.

IGFs stimulated clonal expansion of 3T3-L1 cells (IGF-I more potently than IGF-II (EC $50: 30 \mathrm{nM}$ and $50 \mathrm{nM})$ ). npIGFBP-1 inhibited IGF-I ( $50 \mathrm{nM})$ clonal expansion at a 5:1 molar ratio $(P<0 \cdot 01)$, whereas pIGFBP-1 (purified from HepG2 cell medium) abolished clonal expansion at a 1:1 molar ratio $(P<0 \cdot 005)$. In contrast, IGF-II-induced clonal expansion was inhibited $100 \%$ at a 1:1 molar ratio of npIGFBP-1.
\end{abstract}

In mature adipocytes, IGF-I was equipotent with insulin in stimulating glucose uptake $\left(\mathrm{EC}_{50}: 10 \mathrm{nM}\right)$ and inhibiting isoproterenol-induced lipolysis $\left(\mathrm{EC}_{50}: 15 \mathrm{nM}\right)$. npIGFBP-1 completely reversed IGF-I effects at a 1:1 molar ratio $(P<0 \cdot 01)$.

In summary, IGFs rather than insulin are potent regulators of clonal expansion in 3T3-L1 preadipocytes. Importantly, IGFs are equipotent with insulin in regulating adipocyte metabolism. IGFBP-1 inhibits IGF effects on preadipocyte proliferation and adipocyte metabolism, with pIGFBP-1 being more potent than npIGFBP-1 at inhibiting mitogenic actions. Since IGFBP-1 is acutely regulated by insulin, this could have important consequences in hyperinsulinaemic and insulin-resistant states.

Journal of Endocrinology (2002) 174, 289-297

\section{Introduction}

The amount of fat stored by an individual is regulated by the number and size of existing adipocytes. Therefore regulation of the proliferation of adipocyte precursor cells and their differentiation into mature adipocytes are important determinants of the obese phenotype. This potential for increasing the number of adipocytes continues throughout life. Once established, adipocytes have the capacity to store triglycerides, but the degree of uptake or release is tightly regulated, particularly by insulin.

In vitro data have implicated insulin-like growth factors (IGFs) as important regulators of preadipocyte proliferation and differentiation (Smith et al. 1988, Guller et al. 1989) and in vivo free IGF levels are increased in obesity (Nam et al. 1997). There are data which suggest that IGFs may also be equipotent with insulin in promoting glucose uptake and storage in adipocytes (Shimizu et al. 1986, Weiland et al. 1990, 1991). However, other data suggest that IGFs are more potent regulators of growth and are not as potent as insulin in regulating the metabolic actions (Shimizu et al. 1986, Tomas et al. 1993).
The free fraction of IGFs are thought to be regulated by IGF-binding proteins (IGFBPs). Of all the IGFBPs, IGFBP-1, uniquely, is acutely negatively regulated by insulin (Unterman et al. 1991). Thus IGFBP-1 represents an important link between the insulin and IGF systems that might be profoundly affected by the development of obesity, hyperinsulinaemia and diabetes mellitus.

IGFBP-1 in the circulation exists in a highly phosphorylated state (Koistinen et al. 1993). Studies of the effects of IGFBP-1 on IGF actions have used either recombinant human (rh) IGFBP-1 or IGFBP-1 purified from amniotic fluid (Okajima et al. 1993, Lee et al. 1996). The former is a non-phosphorylated protein and the latter is deficient in the highly phosphorylated IGFBP-1. The phosphorylation status of the IGFBP-1 used in in vitro studies may be an important determinant of its ability to modulate IGF actions, as the highly phosphorylated form has a much higher affinity for IGF-I than the non-phosphorylated form (Jones et al. 1993, Westwood et al. 1997).

To determine the potential for IGFBP-1 to inhibit the mitogenic and metabolic actions of IGFs, we have used the 3T3-L1 preadipocytes as a model of the mitogenic actions 
of IGFs and mature 3T3-L1 adipocytes as a model of the metabolic actions of IGFs. We have also compared the ability of recombinant and phosphorylated IGFBP-1 to modulate IGF actions in 3T3-L1 cells.

\section{Materials and Methods}

\section{Cell culture}

The preadipocyte 3T3-L1 cell line was obtained from the American type culture collection and grown in Dulbecco's modified Eagle's medium (DMEM) Hepes modification (Sigma, Poole, Dorset, UK) containing glutamine (4 mM), pyruvate $(1 \mathrm{mM})$ and $10 \%$ fetal calf serum (FCS). The human hepatocyte carcinoma cell line HepG2 was obtained from the European collection of cell cultures and grown in DMEM Hepes modification containing 10\% FCS, glutamine $(4 \mathrm{mM})$, pyruvate $(1 \mathrm{mM})$ and $1 \%$ nonessential amino acids. The rhIGFBP-1 used in this study was a kind gift from Genentech (San Francisco, CA, USA).

\section{Differentiation of 3T3-L1 preadipocytes}

3T3-L1 preadipocytes were seeded at a density of $5 \times 10^{4}$ cells/ml (day 0 ) and grown until 2 days post-confluent (day 8). The medium was then changed to differentiation medium (DMEM +10\% FCS + glutamine and pyruvate + $2 \mu \mathrm{M}$ insulin $+0.5 \mathrm{mM}$ 3-isobutyl-L-methylxanthine + $0 \cdot 25 \mu \mathrm{M}$ dexamethasone). Cells were maintained in this medium for 2 days and on day 10 the medium was changed back to normal growth medium. Untreated control cells were maintained in differentiation medium without IGF-I or insulin. Triglyceride droplets could be observed in differentiated cells from day 14. In all experiments using differentiated 3T3-L1 adipocytes, greater than $90 \%$ of the cells acquired the adipocyte phenotype.

\section{Purification of phosphorylated IGFBP-1}

Phosphorylated IGFBP-1 was purified from serum-free medium that had been conditioned by HepG2 cells, for $48 \mathrm{~h}$. The IGFBP-1 was concentrated by ammonium sulphate precipitation at $65 \%$ (65 g ammonium sulphate in $100 \mathrm{ml}$ medium at room temperature), the pellet was dissolved in $10 \mathrm{ml}$ phosphate-buffered saline (PBS) followed by partial purification by precipitation at 35\% ammonium sulphate ( $3.5 \mathrm{~g}$ in $10 \mathrm{ml}$ at room temperature). The IGFBP-1 sample was then de-lipidated by precipitation of the IGFBP-1 with cold acetone. Any traces of acetone were removed prior to purification of the IGFBP-1 by size-exclusion HPLC on a Biosep SECS2000 column (Phenomenex, Macclesfield, Cheshire, UK). HepG2 cells secrete all phosphoforms of IGFBP-1 and therefore the non-phosphorylated isoform was then removed from the sample by immunoprecipitation with the 6305 monoclonal antibody (MAb) $(0 \cdot 1 \mu \mathrm{g} \mathrm{MAb} / \mathrm{mg}$ total protein; $6305 \mathrm{MAb}$ was generously provided by Medix Biochemica, Kauniainen, Finland), which recognises all IGFBP-1 phosphoforms except the highly phosphorylated species. The remaining IGFBP-1 was analysed by SDS-PAGE and stained for total protein using colloidal gold (Bio-Rad). Although IGFBP-1 was not purified to homogeneity (several other bands were present), IGFBP-1 was the only IGFBP in the sample. When this preparation was used, the IGFBP-1 was immunoprecipitated and the remaining supernatant was added to cells to determine whether the effect observed was due to the IGFBP-1 content of the sample or the contaminating proteins.

\section{Clonal expansion of 3T3-L1 cells}

3T3-L1 cells were plated into 12 -well plates at a density of $5 \times 10^{4}$ cells $/ \mathrm{ml}$ and grown until 2 days post-confluent (day 8 from plating). Cells were then placed into differentiation medium, containing increasing concentrations of IGF-I (GroPep, Adelaide, SA, Australia), IGF-II or insulin (Sigma), for 2 days. On day 10, cells were removed from the wells by the addition of $0.5 \mathrm{ml}$ trypsin $(1 \times$, Sigma) and pelleted by centrifugation $(1000 \mathrm{~g})$, before counting cells on a haemocytometer using trypan blue to assess viability. Statistical significance was assessed using the non-parametric Mann-Whitney test.

\section{Glucose uptake by mature 3T3-L1 adipocytes}

Mature 3T3-L1 adipocytes (day 16 from plating) were serum and glucose starved for $1 \mathrm{~h}$ in Hepes-buffered saline $\left(150 \mathrm{mM} \mathrm{NaCl}, 5 \mathrm{mM} \mathrm{KCl}, 5 \mathrm{mM} \mathrm{MgSO}{ }_{4}, 1 \mathrm{mM} \mathrm{CaCl}_{2}\right.$ $15 \mathrm{mM}$ Hepes, $\mathrm{pH} \mathrm{7.2)}$ before the addition of IGF-I, IGF-II or insulin, at increasing concentrations, for $30 \mathrm{~min}$. Glucose (2 mM 2-deoxy-glucose, $10 \mu \mathrm{Ci} / \mathrm{ml}^{3} \mathrm{H}$-2-deoxyglucose; Amersham Pharmacia) was added to each well for $15 \mathrm{~min}$. Glucose uptake was then stopped by the addition of phloretin $(2 \mathrm{mM})$. Adipocytes were washed with icecold PBS and lysed in $500 \mu \mathrm{l} 0 \cdot 1 \mathrm{M} \mathrm{NaOH}$. Four hundred and fifty microlitres were transferred into a scintillation vial and $4 \mathrm{ml}$ scintillation fluid was added and counted in a $\beta$-counter for $1 \mathrm{~min}$. The remaining $50 \mu \mathrm{l}$ was used to measure the total protein content of the cell suspension.

\section{Hormone-sensitive lipase activity in mature adipocytes}

3T3-L1 preadipocytes were grown until 2 days postconfluent and differentiated as described above. On day 18 the mature adipocytes were serum starved for $1 \mathrm{~h}$ in Krebs-Henseleit buffer pH 7·4 (Sigma). Cells were treated with isoproterenol $(10 \mathrm{nM}$ in Krebs-Henseleit buffer, $\mathrm{pH} 7 \cdot 4+2 \%$ bovine serum albumin (BSA) (low in IGFs; First Link UK Ltd, Brierley Hill, West Midlands, UK) for 
A

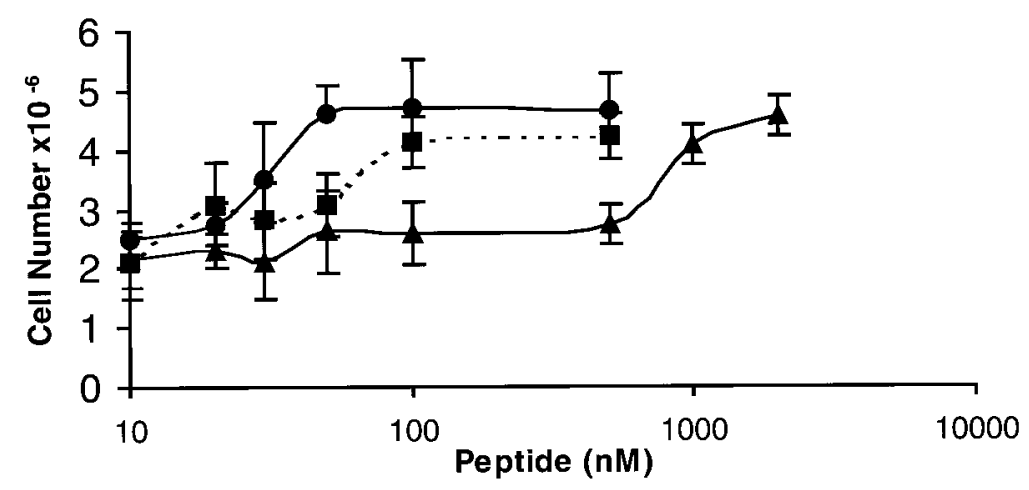

B

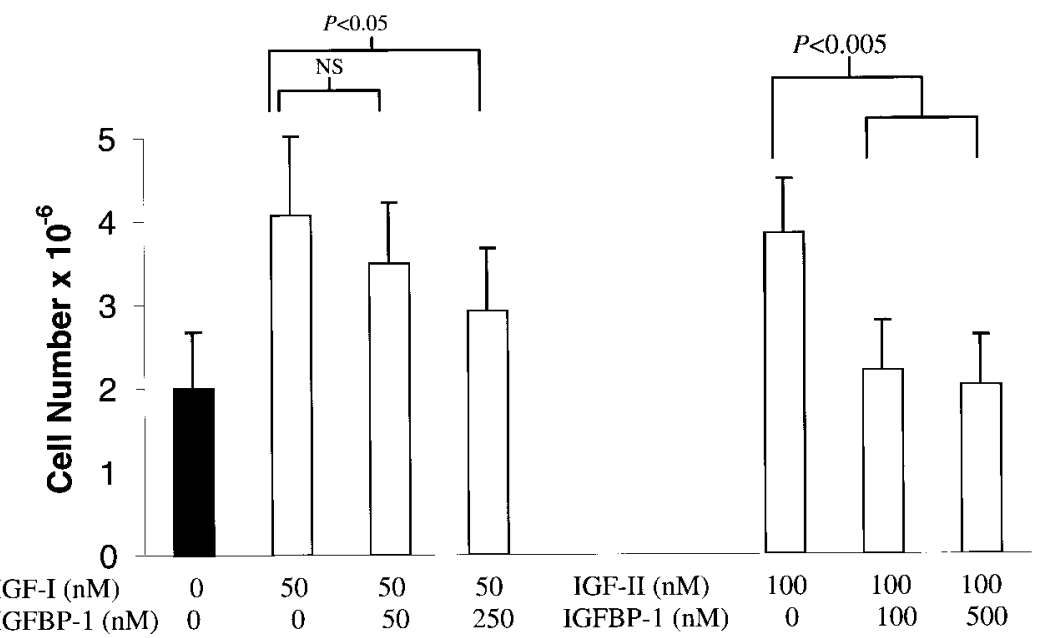

Figure 1 Effect of IGF-I, IGF-II, insulin and non-phosphorylated (np)IGFBP-1 on the clonal expansion of 3T3-L1 cells. Cells were seeded in 12-well plates and grown until 2 days post-confluent (day 8) before induction of differentiation with IGF-I (-), IGF-II ( $\mathbf{\square})$ or insulin $(\Delta)(A)$ or cells were given IGF-I or IGF-II \pm recombinant human (rh)IGFBP-1 (B). All IGFBP-1 solutions were pre-incubated with IGF-I for $30 \mathrm{~min}$ at room temperature before being added to cells for 2 days. Triplicate cell counts were obtained for each experiment and the graph represents the mean of four separate experiments \pm S.D. NS, not significant.

$30 \mathrm{~min}$ at $37^{\circ} \mathrm{C}$. The supernatant was collected and assayed for glycerol content by the enzymatic method (Guder et al. 1969).

\section{Results}

The effect of IGFBP-1 on IGF-stimulated clonal expansion

IGF-I stimulated the clonal expansion of 3T3-L1 preadipocytes prior to differentiation (Fig. 1A) as shown by a twofold increase in the number of cells at 2 days postconfluence. IGF-I was the most potent inducer of clonal expansion, having a maximal effect at $50 \mathrm{nM}$ compared with $100 \mathrm{nM}$ for IGF-II and $2 \mu \mathrm{M}$ for insulin (Fig. 1A). When non-phosphorylated (np) IGFBP-1 (recombinant human) was co-incubated with IGF-I, a 5:1 molar ratio significantly inhibited IGF-I-stimulated clonal expansion, although cell number was not returned to control values. However, a 1:1 molar ratio of npIGFBP-1:IGF-I did not significantly inhibit IGF effects (Fig. 1B). In contrast, npIGFBP-1 was a potent inhibitor of IGF-II, since IGFII-stimulated clonal expansion was completely inhibited by a 1:1 molar ratio of npIGFBP-1:IGF-II.

IGFBP-1 purification and its effects on IGF-stimulated clonal expansion

IGFBP-1 in the circulation normally exists in a highly phosphorylated state. Therefore we purified phosphorylated IGFBP-1 from medium conditioned by 


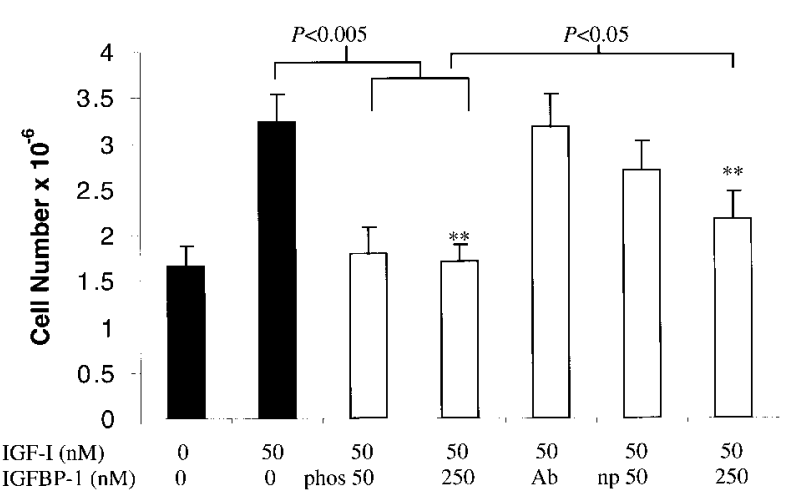

Figure 2 Analysis of IGFBP-1 purified from HepG2-conditioned medium and its effects on IGF-stimulated clonal expansion. Cells were seeded in 12-well plates and induced to differentiate on day 8 with IGF-I \pm phosphorylated (phos) IGFBP-1 or nplGFBP-1. $\mathrm{Ab}$ represents phosphorylated IGFBP-1 immunoprecipitated with MAb 6303 as a control. All IGFBP-1 solutions were pre-incubated with IGF-I for $30 \mathrm{~min}$ at room temperature before being added to cells for 2 days. Triplicate cell counts were obtained and each histogram represents the mean of four separate experiments \pm S.D., the npIGFBP-1 data represent eight experiments \pm S.D. ${ }^{* *} P<0 \cdot 05$.

human HepG2 cells as these cells secrete a mixture of non-phosphorylated, highly phosphorylated and three lesser phosphorylated forms. The IGFBP-1 was purified by successive ammonium sulphate and acetone precipitations followed by size exclusion HPLC. The monoclonal antibody 6305, which only recognises the non- and lesser phosphorylated forms of IGFBP-1, was used to precipitate these forms in order to enrich the IGFBP-1 preparation with the highly phosphorylated form.

Phosphorylated IGFBP-1 was more potent than npIGFBP-1 at inhibiting IGF-I-stimulated clonal expansion since incubation at a 1:1 molar ratio completely reversed the IGF-I effects (Fig. 2), whilst npIGFBP-1 again only partially inhibited at a 5:1 molar ratio. To rule out the possibility that contaminating proteins may be contributing to this effect, IGFBP-1 was immunoprecipitated with the 6303 monoclonal antibody, which removes all IGFBP-1 phosphoforms. Cells were then treated with the remaining supernatant. When the IGFBP-1 was removed from the sample, the residue had no effect on IGF-I-stimulated clonal expansion.

\section{IGFBP-1 inhibits IGF-stimulated glucose uptake}

3T3-L1 cells were induced to differentiate and glucose uptake was increased significantly 2 days after differentiation was induced. This increase in glucose uptake was not sensitive to insulin, as cells that were not stimulated with insulin accumulated labelled glucose to almost the same degree as insulin-stimulated cells (data not shown). The developing adipocytes became insulin sensitive on day 6 after differentiation and therefore all subsequent studies were on cells between days 6 and 8 after induction of differentiation.
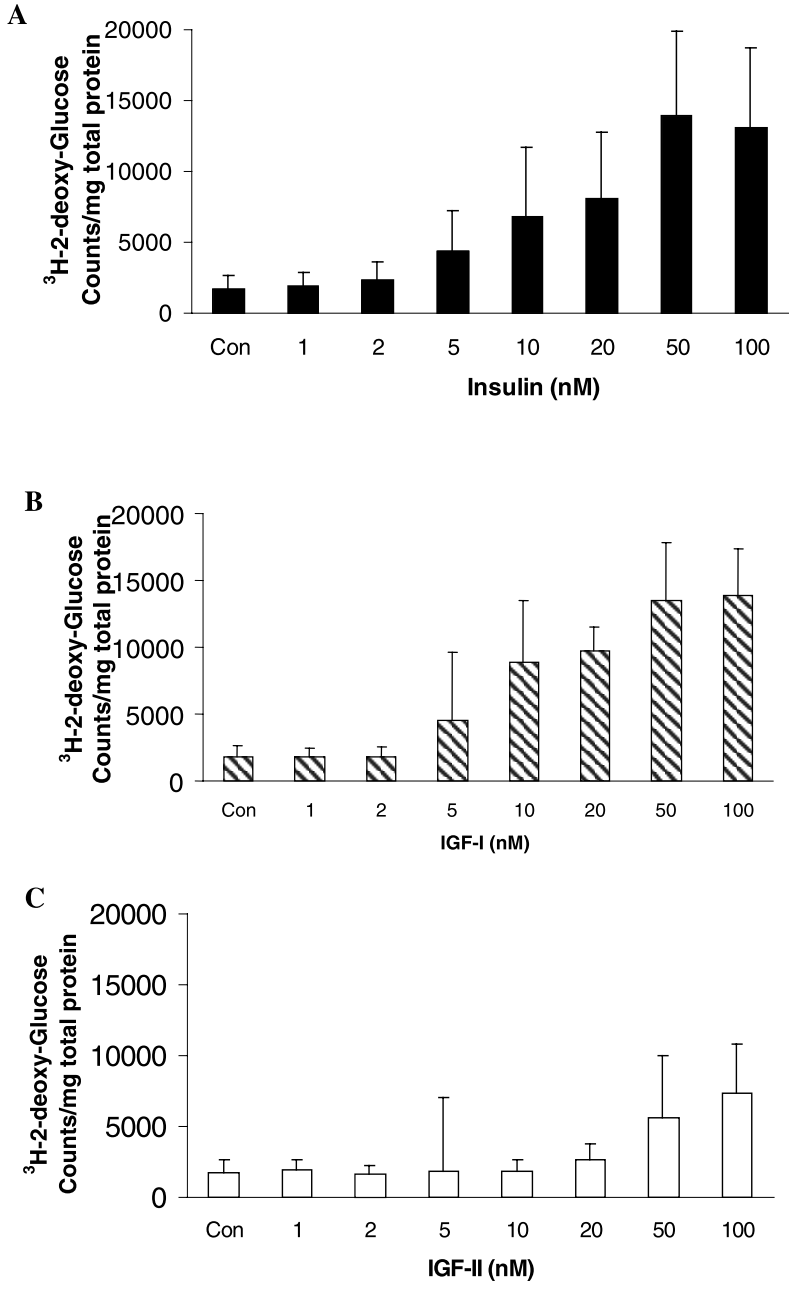

Figure 3 Effect of insulin, IGF-I and IGF-II on glucose uptake. Mature 3T3-L1 adipocytes (day 6 post differentiation) were serum and glucose starved for $1 \mathrm{~h}$ before being treated with increasing concentrations of insulin (A), IGF-I (B) and IGF-II (C) for $30 \mathrm{~min}$. Uptake of ${ }^{3} \mathrm{H}$-2-deoxy-glucose was then measured in triplicate over a 15-min period. Each histogram represents the mean of five separate experiments \pm S.D. Con, control.

Insulin caused a dose-dependent increase in glucose uptake in mature 3T3-L1 adipocytes (Fig. 3A), 5-100 nM insulin caused a significant increase above control values. IGF-I was equipotent with insulin $\left(\mathrm{EC}_{50}: 10 \mathrm{nM}\right.$ for insulin and IGF-I) in promoting glucose uptake in mature adipocytes (Fig. 3B). IGF-II was much less potent $\left(\mathrm{EC}_{50}\right.$ : $100 \mathrm{nM}$ ) than both insulin and IGF-I in stimulating glucose uptake (Fig. 3C).

npIGFBP-1 completely inhibited IGF-I-stimulated glucose uptake at 1:1 and 5:1 molar ratios (Fig. 4A). IGFBP-1 alone had no effect on basal glucose uptake and did not inhibit insulin-stimulated glucose uptake (Fig. 4B). 


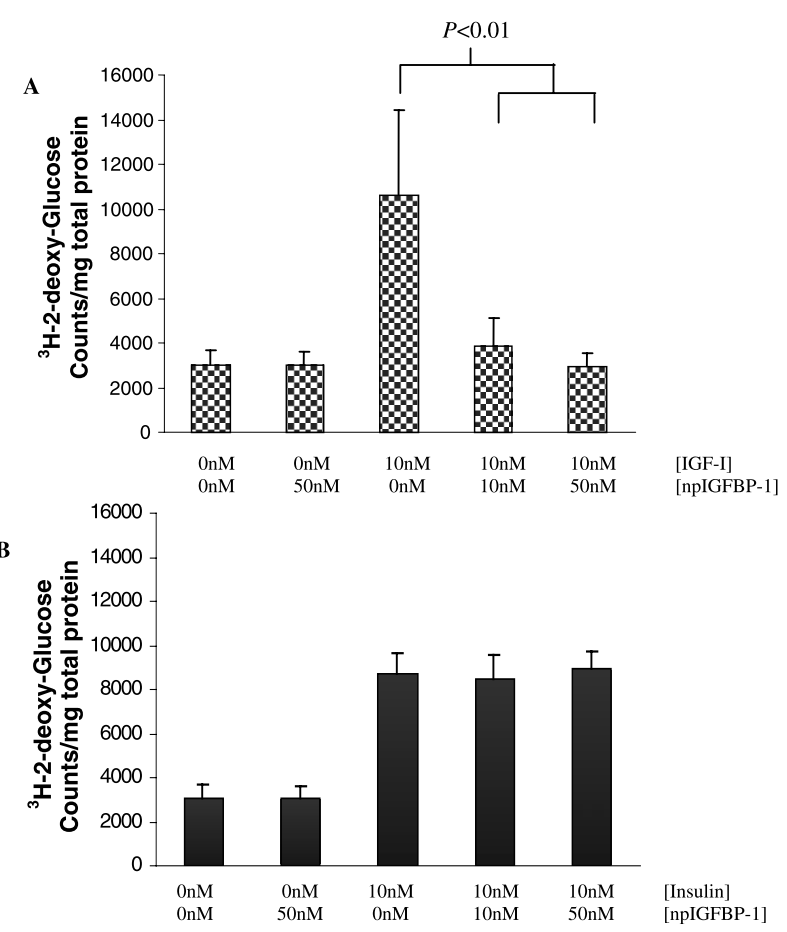

Figure 4 Effect of IGFBP-1 on IGF-I- and insulin-stimulated glucose uptake. 3T3-L1 mature adipocytes were serum and glucose starved for $1 \mathrm{~h}$ before being treated with either $10 \mathrm{nM}$ IGF-I (A) or $10 \mathrm{nM}$ insulin (B) with and without IGFBP-1. Cells were treated for 30 min and uptake of ${ }^{3} \mathrm{H}$-2-deoxy-glucose was measured in triplicate over a 15-min period. Each histogram represents the mean of three separate experiments \pm S.D.

\section{IGFBP-1 reverses IGF-I inhibition of lipolysis}

These experiments assessed the ability of IGFs to mimic insulin's actions in inhibiting hormone-sensitive lipase. Lipolysis was stimulated with the catecholamine isoproterenol and assessed by measuring glycerol release by mature adipocytes as a result of triglyceride hydrolysis. Cells treated with isoproterenol $(10 \mathrm{nM})$ demonstrated an eightfold increase in glycerol release compared with untreated adipocytes (Fig. 5). Insulin (20 nM) inhibited the isoproterenol-stimulated lipolysis to control values (Fig. 5A). IGF-I, also at $20 \mathrm{nM}$, was equipotent with insulin in inhibiting the increased lipolysis (Fig. 5B). npIGFBP-1 completely reversed the IGF-I inhibition of isoproterenol-stimulated lipolysis at 1:1 and 5:1 molar ratios of IGFBP-1:IGF-I (Fig. 6A). IGFBP-1, alone, had no effect on basal or isoproterenol-stimulated glycerol release from mature adipocytes (Fig. 6) and npIGFBP-1 did not alter the effects of insulin (Fig. 6B).

\section{Discussion}

This study demonstrates that in 3T3-L1 cells in vitro, IGF-I, rather than insulin, is more likely to be the main regulator of preadipocyte proliferation. In addition, IGFBP-1 inhibits the IGF-stimulated proliferation of 3T3-L1 preadipocytes. Furthermore, IGFBP-1 inhibits IGF-I-stimulated glucose uptake and reverses IGF-I inhibition of lipolysis, both of which are important determinants of the metabolic function of adipocytes.

IGF-I is markedly more potent than insulin in stimulating the clonal expansion of 3T3-L1 preadipocytes prior to differentiation into mature adipocytes. The doubling in cell number that is associated with clonal expansion occurred with an $\mathrm{EC}_{50}$ of $30 \mathrm{nM}$ for IGF-I, $50 \mathrm{nM}$ for IGF-II and $1000 \mathrm{nM}$ for insulin. These observations suggest that both IGFs and insulin are acting through the type 1 IGF receptor (IGFR), as supraphysiological concentrations of insulin were required to have the same effect as IGFs. This is consistent with data showing that 3T3-L1 preadipocytes express large numbers of IGFRs but few, if any, insulin receptors (Smith et al. 1988). Our results showed that IGF-I was more potent than IGF-II, suggesting that IGF-II was acting through the type 1 IGFR where the affinity is higher for IGF-I than IGF-II (Weber et al. 1992).

3T3-L1 preadipocytes secrete IGFBP-3, IGFBP-4 and an unknown $30 \mathrm{kDa}$ IGFBP. During differentiation they also produce a $34 \mathrm{kDa}$ form of IGFBP-2 (Boney et al. 1994). However, we found that these binding proteins were produced at very low levels, since conditioned medium had to be concentrated tenfold in order to detect the IGFBPs by Western ligand blot (authors' unpublished data). Therefore these IGFBPs are unlikely to make a major contribution to the regulation of endocrine IGFs.

Of all the IGFBPs, the characteristics of IGFBP-1 suggest it is likely to be important in regulating the metabolic effects of IGFs (e.g. acutely inhibited by insulin (Unterman et al. 1991)). In the circulation of normal, non-pregnant individuals, IGFBP-1 is present as a highly phosphorylated form. Other studies have used either recombinant IGFBP-1 which is non-phosphorylated (Cox et al. 1994, Lee et al. 1996) or IGFBP-1 purified from amniotic fluid which is deficient in the highly phosphorylated form (Frauman et al. 1989, Burch et al. 1990, Angervo et al. 1991, Liu et al. 1991, Lewitt et al. 1993). We therefore purified phosphorylated IGFBP-1 from HepG2-conditioned medium and found it was more potent than npIGFBP-1 since it completely reversed the effects of IGF-I at a 1:1 molar ratio, while at this molar ratio npIGFBP-1 did not significantly inhibit IGF mitogenic actions. These findings are consistent with the phosphorylated IGFBP-1 having a higher affinity for IGF-I than the npIGFBP-1 and being able to out-compete the IGFR for IGF-I binding.

The only other study to explore the effects of phosphorylated IGFBP-1 has reported that a 5:1 molar ratio of either npIGFBP-1 or phosphorylated IGFBP-1 to IGF-I was required to completely inhibit IGF-I-stimulated 

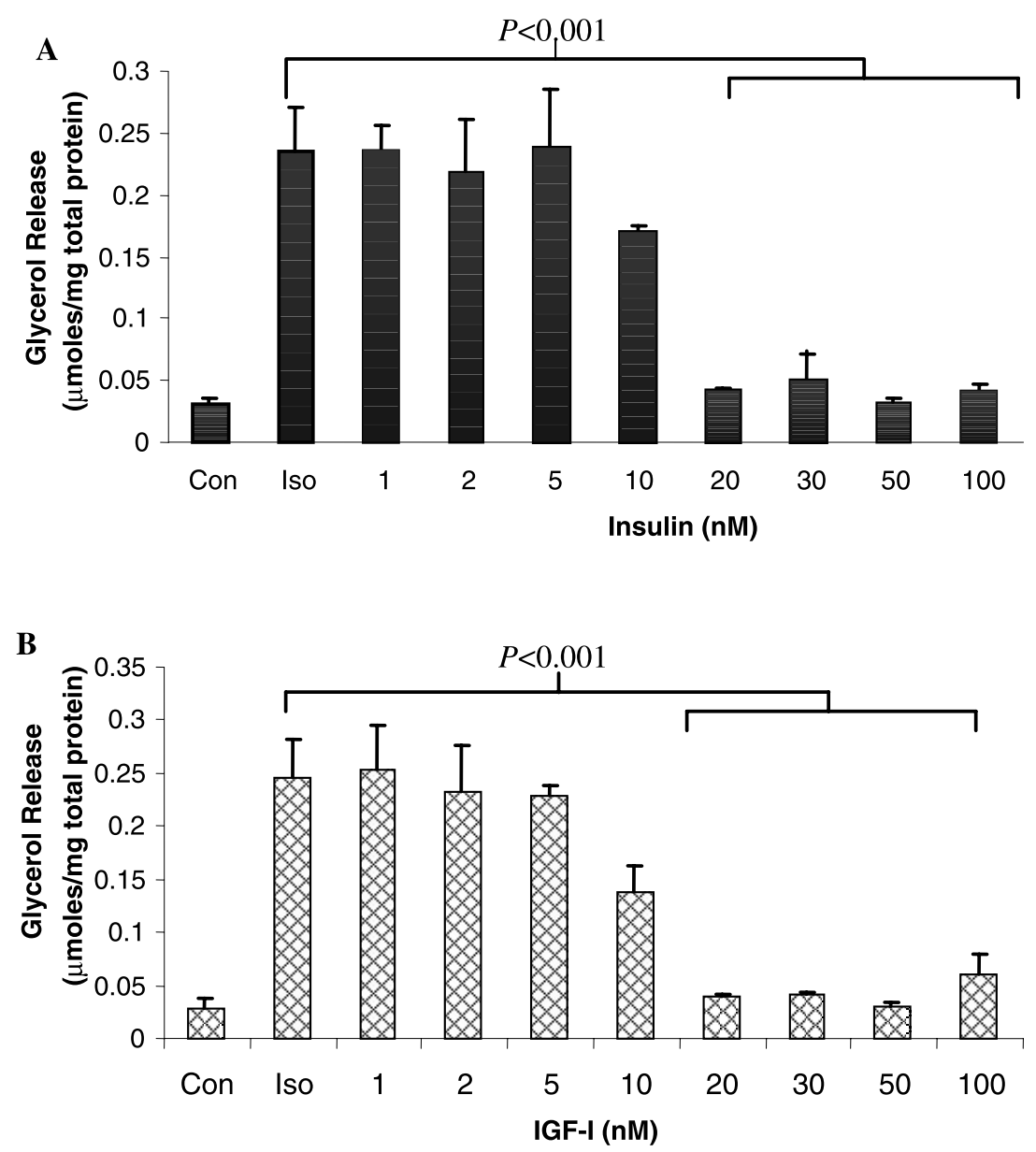

Figure 5 Inhibition of isoproterenol-stimulated lipolysis by insulin and IGF-I. 3T3-L1 cells were grown until 2 days post-confluent (day 8 ) and differentiated. On day 10, cells were returned to normal growth medium and maintained for a further 8 days. Cells were serum starved for $1 \mathrm{~h}$ before treatment with insulin/IGF-I and/or isoproterenol. Control cells (Con) represent cells incubated with buffer alone for $30 \mathrm{~min}$. Iso, cells stimulated with $10 \mathrm{nM}$ isoproterenol for $30 \mathrm{~min}$. Cells were pre-incubated with a range of insulin (A) and IGF-I (B) concentrations for $30 \mathrm{~min}$ before being stimulated with $10 \mathrm{nM}$ isoproterenol for $30 \mathrm{~min}$. Each histogram represents the mean of four separate experiments \pm S.D.

protein synthesis in skeletal muscle cells (Frost \& Lang 1999), although significant inhibition was seen at lower molar ratios of phosphorylated IGFBP-1 (half maximal at 1·5:1). That study used phosphorylated IGFBP-1 (purchased from Sigma) which was purified from HepG2conditioned medium and therefore contains a mixture of phosphoforms similar to that purified for this study. In our study, the effects we observed with differentially phosphorylated IGFBP-1 are likely to be due to this modification of IGFBP-1 as we did not observe any dimer formation and IGFBP-1 incubated with the preadipocytes and adipocytes was not subject to proteolysis (data not shown).

Interestingly, IGF-II was a potent inducer of clonal expansion and was more potently inhibited by npIGFBP-1 than IGF-I. The phosphorylation status of IGFBP-1 affects its affinity for IGF-I but not IGF-II (Westwood et al. 1997). We speculate that npIGFBP-1 can compete for IGF-II binding with the type 1 IGFR better than it can for IGF-I binding and that IGFBP-1 needs to be in the highly phosphorylated state before it can adequately compete for binding of IGF-I.

In mature adipocytes, we found that IGF-I is equipotent with insulin in promoting glucose uptake, with an $\mathrm{EC}_{50}$ of $10 \mathrm{nM}$, while IGF-II was much less potent, which is in agreement with Weiland et al. (1990, 1991). It has been shown that the number of insulin receptors increases approximately 25-fold to between 170000 and 250000 per cell with differentiation, while the number of IGFRs (13000 sites/cell) remains constant (Smith et al. 1988). However, approximately $70 \%$ of the IGFR-binding sites 

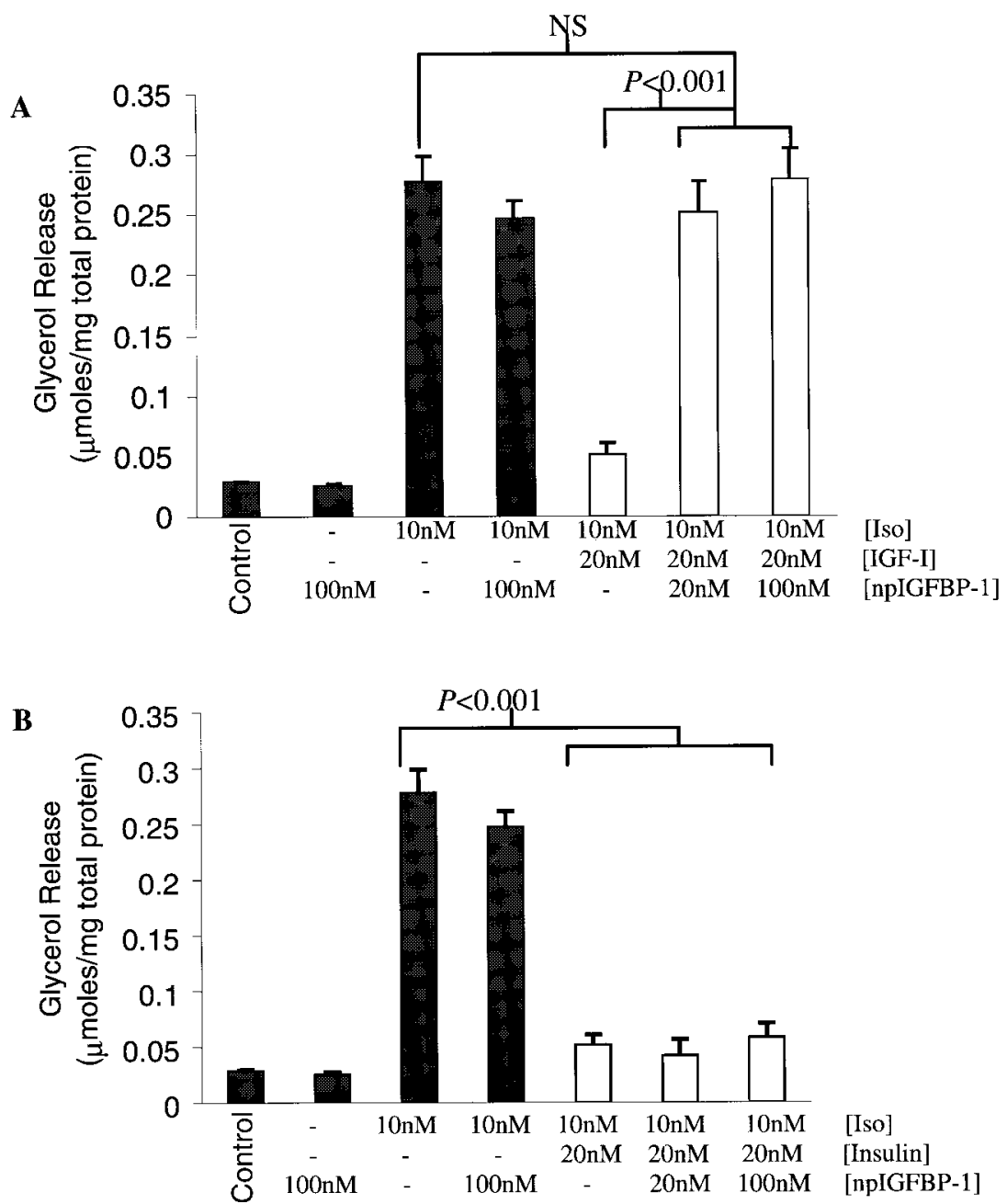

Figure 6 Effect of IGFBP-1 on insulin and IGF-I inhibition of isoproterenol-stimulated lipolysis. 3T3-L1 cells were grown until 2 days post-confluent (day 8) and differentiated. On day 10 , cells were returned to normal growth medium and maintained for a further 8 days. Adipocytes were serum starved for $1 \mathrm{~h}$ before the addition of insulin/IGF-I and isoproterenol. Control bars represent adipocytes incubated with buffer alone for $30 \mathrm{~min}$. Iso, cells treated with $10 \mathrm{nM}$ isoproterenol for $30 \mathrm{~min}$. Adipocytes were pre-incubated with either IGF-I (A) or insulin (B) with and without IGFBP-1. Controls with IGFBP-1 (100 nM IGFBP-1 and Iso + 100 nM IGFBP-1) represent the highest levels of IGFBP-1 used, i.e. the same concentration as in 5:1 molar ratio. Medium from triplicate wells was then assayed for glycerol content. Each histogram represents the mean of three separate experiments \pm S.D.

are expressed as IGFR/insulin receptor hybrids (Bailyes et al. 1997). Thus, in adipocytes, the presence of hybrid receptors retains the capacity for binding IGF-I.

In preadipocytes, we found that recombinant, npIGFBP-1 inhibited IGF effects on glucose uptake at a $5: 1$ molar ratio which is similar to the findings of Okajima et al. (1993) who used IGFBP-1 purified from amniotic fluid, which contains non- and lesser phosphorylated IGFBP-1. It was suggested by Okajima et al. (1993) that IGFBP-1 in the circulation $(10-200 \mu \mathrm{g} / \mathrm{l})$ would be insufficient to inhibit IGF-I levels in the circulation
$(200 \mu \mathrm{g} / \mathrm{l})$, since this represented a $0 \cdot 1: 1$ molar ratio of IGFBP-1:IGF-I. However, it is thought that IGFBP-1 regulates the free fraction of IGFs and it has been estimated that less than 1\% of the circulating IGF-I is in the free form (Collett-Solberg \& Cohen 1996). This means that the molar ratio of IGFBP-1 to free IGF-I may be as high as 10:1 in the circulation, and this may significantly inhibit IGF-I effects, based on the inhibitory effects we observed.

However, it is interesting to speculate that in vivo IGFBP-1 could inhibit IGF-stimulated glucose uptake in mature adipocytes and therefore influence metabolism in 
fat cells. When mature adipocytes were co-treated with IGFBP-1, a 1:1 molar ratio of npIGFBP-1 completely reversed the IGF-I-stimulated glucose uptake, whilst requiring a 5:1 molar ratio in preadipocytes. Thus IGFBP-1 is better able to compete for IGF-I binding with an IGF/insulin hybrid receptor than it can with a mature IGFR in preadipocytes. It may therefore be that the IGF/insulin hybrid receptor, whilst preferentially binding IGF-I, does so with a lower affinity than the mature IGFR. Current data suggest that this is not the case as it has been reported that IGFR and IGF/insulin hybrid receptors have similar affinities (Soos et al. 1993). These studies were performed in solution and it has been observed that the insulin receptor binds insulin with tenfold higher affinity in solution than in the membrane (K Siddle, personal communication). It therefore remains possible that the affinity of the IGF/insulin hybrid receptor may be different from that of the IGFR in intact cells.

Importantly, we have also shown that IGF-I is equipotent with insulin at inhibiting isoproterenol-stimulated lipolysis. Both insulin and IGF-I inhibited lipolysis with an $\mathrm{EC}_{50}$ of $15 \mathrm{nM}$. IGFs may therefore play a role in the regulation of lipolysis and free fatty acid secretion in adipocytes. This would have important implications in developing insulin resistance, as elevated free fatty acids are thought to cause peripheral insulin resistance leading to type 2 diabetes (Boden 1999). Again a 1:1 molar ratio of npIGFBP-1 completely reversed this IGF-I inhibition of lipolysis whilst having no effect on insulin inhibition of lipolysis. This is consistent with npIGFBP-1 being able to inhibit IGF-I acting through IGF/insulin hybrid receptors more potently than mature IGFR.

In summary, IGF-I mediates the clonal expansion of preadipocyte cells prior to differentiation and is equipotent with insulin in promoting glucose uptake and inhibiting lipolysis in mature adipocytes. We have found that IGFBP-1 inhibits the mitogenic effects of IGF-I, but is much more potent in inhibiting the metabolic actions of IGFs.

\section{Acknowledgements}

We are grateful to the BBSRC, the Royal Society and Salford Royal Hospital's Trust for financial support.

\section{References}

Angervo M, Koistinen R, Suikkari AM \& Seppala M 1991 Insulin-like growth factor binding protein-1 inhibits the DNA amplification induced by insulin-like growth factor I in human granulosa-luteal cells. Human Reproduction 6 770-773.

Bailyes EM, Nave BT, Soos MA, Orr SR, Hayward AC \& Siddle K 1997 Insulin receptor/IGF-I receptor hybrids are widely distributed in mammalian tissues: quantification of individual receptor species by selective immunoprecipitation and immunoblotting. Biochemical Journal 327 209-215.
Boden G 1999 Free fatty acids, insulin resistance, and type 2 diabetes mellitus. Proceedings of the Association of American Physicians 111 241-248.

Boney CM, Moats-Staats BM, Stiles AD \& D’Ercole AJ 1994 Expression of insulin-like growth factor-I (IGF-I) and IGF-binding proteins during adipogenesis. Endocrinology 135 1863-1868.

Burch WM, Correa J, Shively JE \& Powell DR 1990 The 25-kilodalton insulin-like growth factor (IGF)-binding protein inhibits both basal and IGF-I-mediated growth of chick embryo pelvic cartilage in vitro. Journal of Clinical Endocrinology and Metabolism 70 173-180.

Collett-Solberg PF \& Cohen P 1996 The role of the insulin-like growth factor binding proteins and the IGFBP proteases in modulating IGF action. Endocrinology and Metabolism Clinics of North America 25 591-614.

Cox GN, McDermott MJ, Merkel E, Stroh CA, Ko SC, Squires CH, Gleason TM \& Russell D 1994 Recombinant human insulin-like growth factor (IGF)-binding protein-1 inhibits somatic growth stimulated by IGF-I and growth hormone in hypophysectomized rats. Endocrinology 135 1913-1920.

Frauman AG, Tsuzaki S \& Moses AC 1989 The binding characteristics and biological effects in FRTL5 cells of placental protein-12, an insulin-like growth factor-binding protein purified from human amniotic fluid. Endocrinology 124 2289-2296.

Frost RA \& Lang CH 1999 Differential effects of insulin-like growth factor I (IGF-I) and IGF-binding protein-1 on protein metabolism in human skeletal muscle cells. Endocrinology 140 3962-3970.

Guder W, Weiss L \& Wieland O 1969 Triglyceride breakdown in rat liver. The demonstration of three different lipases. Biochimica et Biophysica Acta 187 173-185.

Guller S, Sonenberg M, Wu KY, Szabo P \& Corin RE 1989 Growth hormone-dependent events in the adipose differentiation of 3T3-F442A fibroblasts: modulation of macromolecular synthesis. Endocrinology 125 2360-2367.

Jones JI, Busby WH Jr, Wright G, Smith CE, Kimack NM \& Clemmons DR 1993 Identification of the sites of phosphorylation in insulin-like growth factor binding protein-1. Regulation of its affinity by phosphorylation of serine 101. Journal of Biological Chemistry 268 1125-1131.

Koistinen R, Angervo M, Leinonen P \& Seppala M 1993 Phosphorylation of insulin-like growth factor-binding protein-1 from different sources. Growth Regulation 3 34-37.

Lee YR, Oshita Y, Tsuboi R \& Ogawa H 1996 Combination of insulin-like growth factor (IGF)-I and IGF-binding protein-1 promotes fibroblast-embedded collagen gel contraction. Endocrinology $1375278-5283$.

Lewitt MS, Saunders H, Lennon AJ, Holman SR \& Baxter RC 1993 Distribution and actions of human IGFBP-1 and IGFBP-3 in the rat. Growth Regulation 3 44-46.

Liu L, Brinkman A, Blat C \& Harel L 1991 IGFBP-1, an insulin like growth factor binding protein, is a cell growth inhibitor. Biochemical and Biophysical Research Communications 174 673-679.

Nam SY, Lee EJ, Kim KR, Cha BS, Song YD, Lim SK, Lee HC \& Huh KB 1997 Effect of obesity on total and free insulin-like growth factor (IGF)-1, and their relationship to IGF-binding protein (BP)-1, IGFBP-2, IGFBP-3, insulin, and growth hormone. International Journal of Obesity and Related Metabolic Disorders 21 355-359.

Okajima T, Iwashita M, Takeda Y, Sakamoto S, Tanabe T, Yasuda T \& Rosenfeld RG 1993 Inhibitory effects of insulin-like growth factor (IGF)-binding proteins-1 and -3 on IGF-activated glucose consumption in mouse BALB/c $3 \mathrm{~T} 3$ fibroblasts. Journal of Endocrinology 136 457-470.

Shimizu M, Torti F \& Roth RA 1986 Characterization of the insulin and insulin-like growth factor receptors and responsitivity of a fibroblast/adipocyte cell line before and after differentiation. Biochemical and Biophysical Research Communications 137 552-558. 
Smith PJ, Wise LS, Berkowitz R, Wan C \& Rubin CS 1988 Insulin-like growth factor-I is an essential regulator of the differentiation of 3T3-L1 adipocytes. Journal of Biological Chemistry 263 9402-9408.

Soos MA, Field CE \& Siddle K 1993 Purified hybrid insulin/ insulin-like growth factor-I receptors bind insulin-like growth factor-I, but not insulin, with high affinity. Biochemical Journal 290 419-426.

Tomas FM, Knowles SE, Owens PC, Chandler CS, Francis GL \& Ballard FJ 1993 Insulin-like growth factor-I and more potent variants restore growth of diabetic rats without inducing all characteristic insulin effects. Biochemical Journal 291 781-786.

Unterman TG, Oehler DT, Murphy LJ \& Lacson RG 1991 Multihormonal regulation of insulin-like growth factor-binding protein-1 in rat H4 IIE hepatoma cells: the dominant role of insulin. Endocrinology 128 2693-2701.

Weber MM, Melmed S, Rosenbloom J, Yamasaki H \& Prager D 1992 Rat somatotroph insulin-like growth factor-II (IGF-II) signaling: role of the IGF-I receptor. Endocrinology 131 2147-2153.
Weiland M, Schurmann A, Schmidt WE \& Joost HG 1990 Development of the hormone-sensitive glucose transport activity in differentiating 3T3-L1 murine fibroblasts. Role of the two transporter species and their subcellular localization. Biochemical Journal 270 331-336.

Weiland M, Bahr F, Hohne M, Schurmann A, Ziehm D \& Joost HG 1991 The signaling potential of the receptors for insulin and insulin-like growth factor I (IGF-I) in 3T3-L1 adipocytes: comparison of glucose transport activity, induction of oncogene c-fos, glucose transporter mRNA, and DNA-synthesis. Journal of Cellular Physiology 149 428-435.

Westwood M, Gibson JM \& White A 1997 Purification and characterization of the insulin-like growth factor-binding protein-1 phosphoform found in normal plasma. Endocrinology $\mathbf{1 3 8}$ $1130-1136$.

Received in final form 21 March 2002

Accepted 10 April 2002 